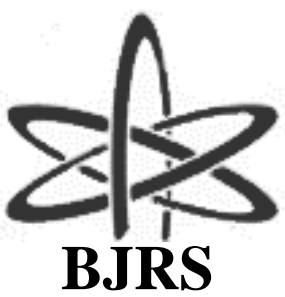

\author{
BRAZILIAN JOURNAL \\ $\mathrm{OF}$ \\ RADIATION SCIENCES \\ 07-2A (2019) 01-13
}

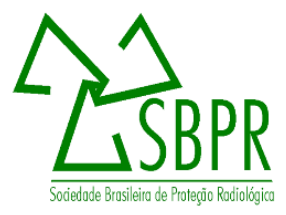

\title{
Constancy tests and quality assurance of the activimeters used in a radiopharmaceutical production facility
}

\author{
Gontijo $^{\mathrm{a}, \mathrm{b}}$ R. M. G., Ferreira ${ }^{\mathrm{a}}$ A. V., Nascimento ${ }^{\mathrm{a}}$ L. T. C., Costa $^{\mathrm{a}}$ F. M., Silva ${ }^{\mathrm{a}}$ J. B.; \\ Mamede $^{\mathrm{a}, \mathrm{b}} \mathrm{M}$. \\ ${ }^{a}$ Radiopharmaceuticals Research and Production Unit, Center of Nuclear Technology Development, 31270-901, \\ Belo Horizonte-MG, Brasil. \\ ${ }^{b}$ Department of Anatomy and Imaging, Federal University of Minas Gerais, 30130-100, Belo Horizonte-MG, Brasil. \\ rodrigo.gontijo@cdtn.br
}

\begin{abstract}
This work presents the evaluation of performance and reliability of the activimeters used at the UPPR/CDTN by carrying out constancy tests within a quality assurance program, based on the CNEN-NN 3.05 Brazilian standard and the manufacturer's manual. Physical inspection, auto zero, background check, detector bias voltage, data check and constancy test were done. In addition, accuracy and precision tests were performed using a set of standard certified radioactive sources $\left({ }^{57} \mathrm{Co},{ }^{133} \mathrm{Ba}\right.$ and $\left.{ }^{137} \mathrm{Cs}\right)$, according to the CNEN NN 3.05 Brazilian standard. Linearity test was also performed to evaluate the response of the equipment over a wide range of activity $(0.29$ to $250 \mathrm{MBq})$ normally used in the routine. The systems are periodically submitted to the quality control tests and the results were compared. The results showed that the UPPR's activimeters were stable over the evaluated period. All values are within the limits presented by the manufacturer's manual and national standard for all tests done. This stability is of major importance for the reliability of all processes involved in molecular imaging. In addition, a quality control checklist was prepared to guide users and to record the results of quality assurance testing to monitor the equipment performance. This task is part of the quality assurance program implemented at UPPR.
\end{abstract}


Keywords: quality assurance, dose calibrator, radiopharmaceutical production facility.

\section{INTRODUCTION}

The Radiopharmaceuticals Research and Production Facility (UPPR) at the Nuclear Technology Development Center of National Nuclear Energy Commission (CDTN/CNEN) produces traditional and new radiopharmaceuticals in a cyclotron facility for positron emission tomography (PET) use. A small animal scanner is used in pre-clinical studies in the development of new radiopharmaceuticals or in new applications of traditional radiopharmaceuticals.

The radionuclides used in research activities at UPPR have short half-lives and are not sealed sources. The injection of correctly measured activity is a way to guarantee that an inconclusive imaging can result and the small animals and patients will not receive a radioactive dose beyond what is necessary.

In this context, activimeters (or dose calibrators) are essential instruments to verify the activity of the radiopharmaceutical after its production and also before the dose administration in small animals or humans for molecular imaging.

This instrument has to be used by trained professionals and has to have its benchmarking performed frequently, which is essential to guarantee the measurements reliability $[1,2,3]$.

The aim of this work was to evaluate the performance and reliability of the activimeters used at the UPPR/CDTN by carrying out constancy tests within a quality assurance program, based on the CNEN-NN 3.05 Brazilian standard [4] and the manufacturer's manual [5].

\section{MATERIALS AND METHODS}

All experiments were carried out at the Radiopharmaceutical Research and Production Facility (UPPR/CDTN/CNEN). 


\subsection{Equipment description}

Two CRC@-25R, Capintec Inc activimeters were used and both consist basically of readout display, a well type ionization chamber and respective dipper device, as illustrated in Figure 1 [5].

Figure 1: Schematic view of activimeter device.

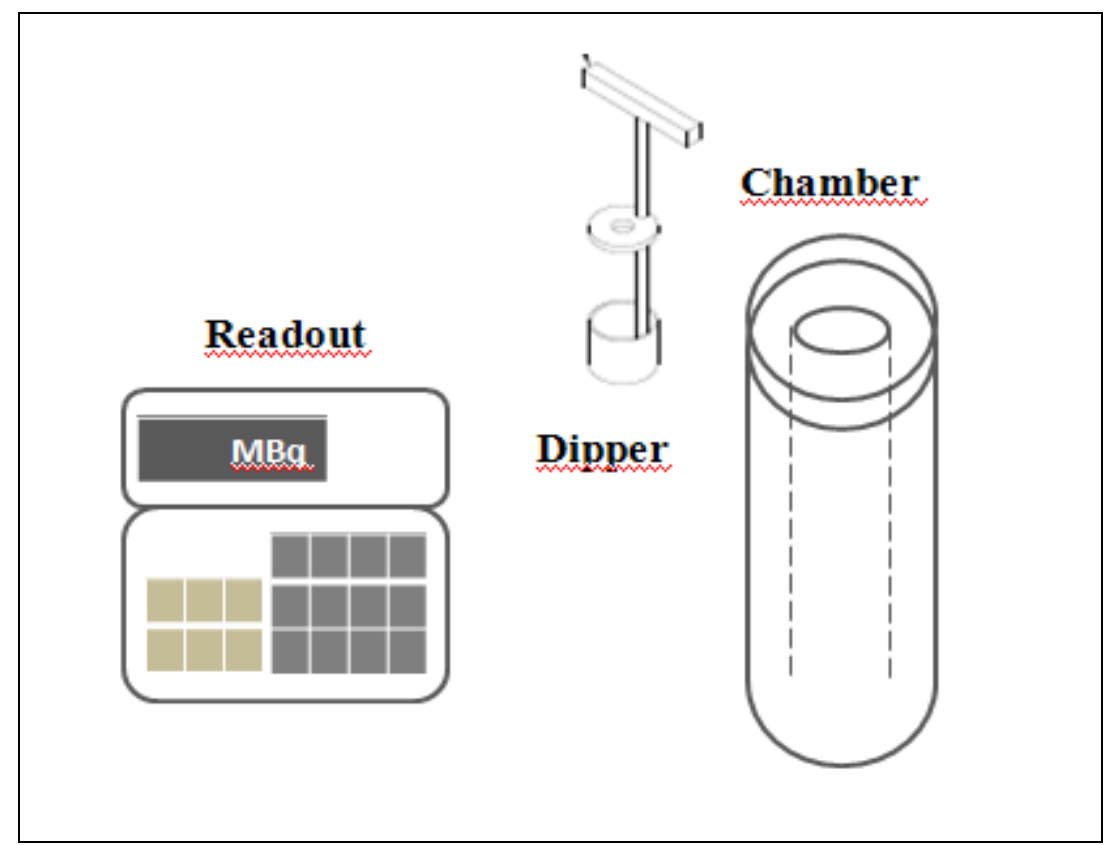

Table 1 contains the main features about the activimeters used in this work.

Table 1: Activimeters features used [5].

\begin{tabular}{cccccc}
\hline Manufacturer / Model & $\begin{array}{c}\text { Gas } \\
\text { Chamber }\end{array}$ & $\begin{array}{c}\text { Height } \\
\text { Chamber }(\mathbf{c m})\end{array}$ & $\begin{array}{c}\text { Diameter } \\
\text { Chamber }(\mathbf{c m})\end{array}$ & $\begin{array}{c}\text { Maximum } \\
\text { Activity }\left({ }^{57} \mathbf{C o}\right)\end{array}$ & Resolution \\
\hline CAPINTEC / CRC ${ }^{\circledR}-25 R^{\circledR}$ & Argon & 43.8 & 17.2 & $\begin{array}{c}206 \mathrm{GBq} \\
(5.57 \mathrm{Ci})\end{array}$ & $\begin{array}{c}0.001 \mathrm{MBq} \\
(0.01 \mu \mathrm{Ci})\end{array}$ \\
\hline
\end{tabular}




\subsection{Standard Sources}

The three recommended by CNEN NN 3.05 standards sources are ${ }^{57} \mathrm{Co},{ }^{133} \mathrm{Ba}$ and ${ }^{137} \mathrm{Cs}$ shown in Figure 2. All have a long half-life and similar energy range to the gamma energy emitted by radionuclides produced or used in experimental routine. Table 2 presents the main physical-chemical properties of the radioactive sources. All sources were provided by Nuclear and Energy Research Institute (IPEN/CNEN), ${ }^{133} \mathrm{Ba}$ and ${ }^{137} \mathrm{Cs}$ have National institute of standards and technology (NIST) traceability certificates and ${ }^{57} \mathrm{Co}$ is under the agreement of European Accreditation - Multilateral Agreement (EA - MLA).

Figure 2: Sealed reference sources for benchmarking of the activimeter. Note: Left to right: ${ }^{57} \mathrm{Co} ;{ }^{133} \mathrm{Ba} ;{ }^{137} \mathrm{Cs}$.

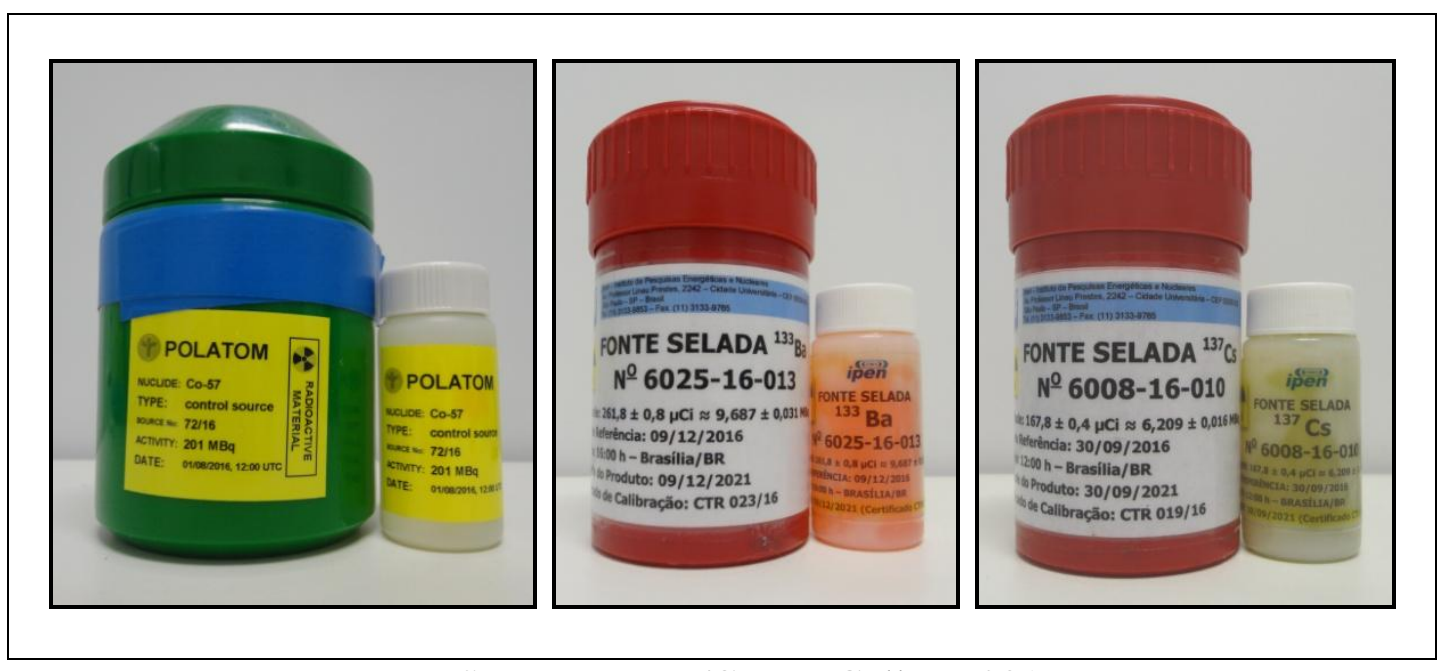

Source: UPPR/CDTN Gallery, 2017

Table 2: Main properties of radionuclides used in benchmarking.

\begin{tabular}{ccccc}
\hline Radionuclide & Main photon energy $(\mathrm{keV}) *$ & Half-Life* & Certified Activity (MBq) & Reference Date \\
\hline${ }^{57} \mathrm{Co}$ & $122.06065 \pm 0.00012$ & $271.74 \mathrm{~d}$ & $201 \pm 5$ & $1^{\text {st }}$ August 2016 \\
${ }^{133} \mathrm{Ba}$ & $356.0129 \pm 0.0007$ & $10.551 \mathrm{y}$ & $9.687 \pm 0.031$ & 09 December 2016 \\
${ }^{137} \mathrm{Cs}$ & $661.657 \pm 0.003$ & $30.08 \mathrm{y}$ & $6.209 \pm 0.016$ & 30 September 2016 \\
\hline
\end{tabular}

* Source: IAEA Live Chart of Nuclides, 2017 [6]. 


\subsection{Methods}

Physical inspection, auto zero, background check, detector bias voltage, data check and constancy test were done. In addition, accuracy and precision tests were performed. A set of standard certified radioactive sources, ${ }^{57} \mathrm{Co},{ }^{133} \mathrm{Ba}$ and ${ }^{137} \mathrm{Cs}$, were used, according to the Brazilian standard. The linearity was checked over the large range of activity (0.29 to $250 \mathrm{MBq})$. This range of activity is normally used in daily routine at the UPPR. Linearity test was performed using decay method of measuring a short lived isotope $\left({ }^{18} \mathrm{~F}\right)$ over time $[4,5]$.

All tests were done based on the information obtained in the CNEN NN 3.05 standard and the manufacturer's manual. Results are presented in Table $3[4,5]$.

Table 3: Periodicity of the benchmarking tests and their limits according to the protocol consulted.

\begin{tabular}{|c|c|c|c|}
\hline \multirow{2}{*}{ Tests } & \multicolumn{2}{|c|}{ Frequency of Tests } & \multirow{2}{*}{$\begin{array}{c}\text { Limits established } \\
{[4,5]}\end{array}$} \\
\hline & CNEN NN 3.05 [4] & Manufacturer Manual [5] & \\
\hline AutoZero & Daily & Daily & $\pm 0.30 \mathrm{mV}$ \\
\hline Background & Daily & Daily & $<0.4 \mathrm{MBq}$ \\
\hline $\begin{array}{l}\text { Detector bias } \\
\text { voltage }\end{array}$ & Daily & Daily & $\pm 15 \mathrm{~V}$ \\
\hline $\begin{array}{c}\text { Data Check } \\
\left({ }^{57} \mathrm{Co} ;{ }^{133} \mathrm{Ba} ;{ }^{137} \mathrm{Cs}\right)\end{array}$ & Daily & Daily & $\pm 5 \%$ \\
\hline Accuracy & Semiannually & Daily & $\pm 10 \%$ \\
\hline Precision & Semiannually & Daily & $\pm 5 \%$ \\
\hline Linearity & Annually & $\begin{array}{c}\text { For improvement } \\
\text { (No recommended period) }\end{array}$ & $\pm 10 \%$ \\
\hline
\end{tabular}


The results of both instruments for daily, semiannually and annually tests were compiled and are presented in next section. The data set presented comprises one year of tests: from 2016 to 2017.

In addition, environmental conditions like temperature and air relative humidity were followed during the period of tests. The equipment manufacturer establishes environmental conditions limits: the instruments should be placed where the temperature is stable within a range of $+10^{\circ} \mathrm{C}$ to $+30^{\circ} \mathrm{C}$ and the maximum relative humidity is $90 \%$ [5].

\section{RESULTS AND DISCUSSIONS}

In this section, the results for physical inspection, daily tests, and accuracy, precision and linearity tests are presented.

Room temperature varied between $18.1{ }^{\circ} \mathrm{C}$ and $23.1{ }^{\circ} \mathrm{C}$ and air relative humidity was always between $34 \%$ and $46 \%$. The environment conditions observed were within limits established by manufacturer over the period evaluated.

\subsection{Physical Inspection and Daily Tests}

Both equipments presented good conditions in physical verification, without any structural damage. All devices and reading display worked properly.

In the all daily tests for both activimeters throughout evaluated period the parameters detector bias voltage, background radiation, zero adjustment and data check showed the message "OK" to continue, which indicates that they are working properly.

The results of auto zero, background and detector bias voltage checks for both activimeters are shown in Figures 3, 4 and 5, respectively. 
Figure 3: Auto zero check results for both activimeters.

(Upper and lower limits are established by manufacturer).

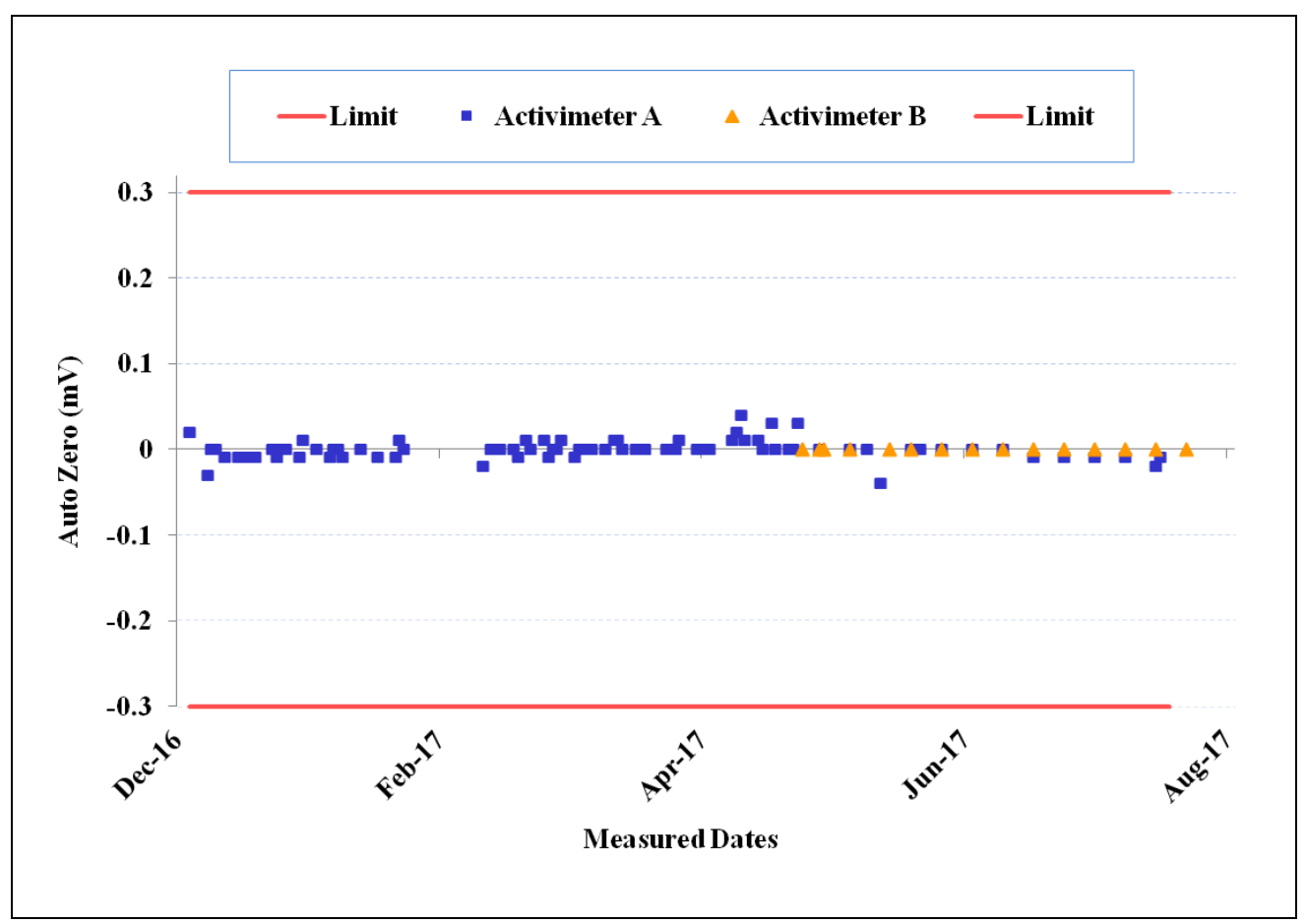

Figure 4: Background check results for both activimeters.

(Upper and lower limits are established by manufacturer).

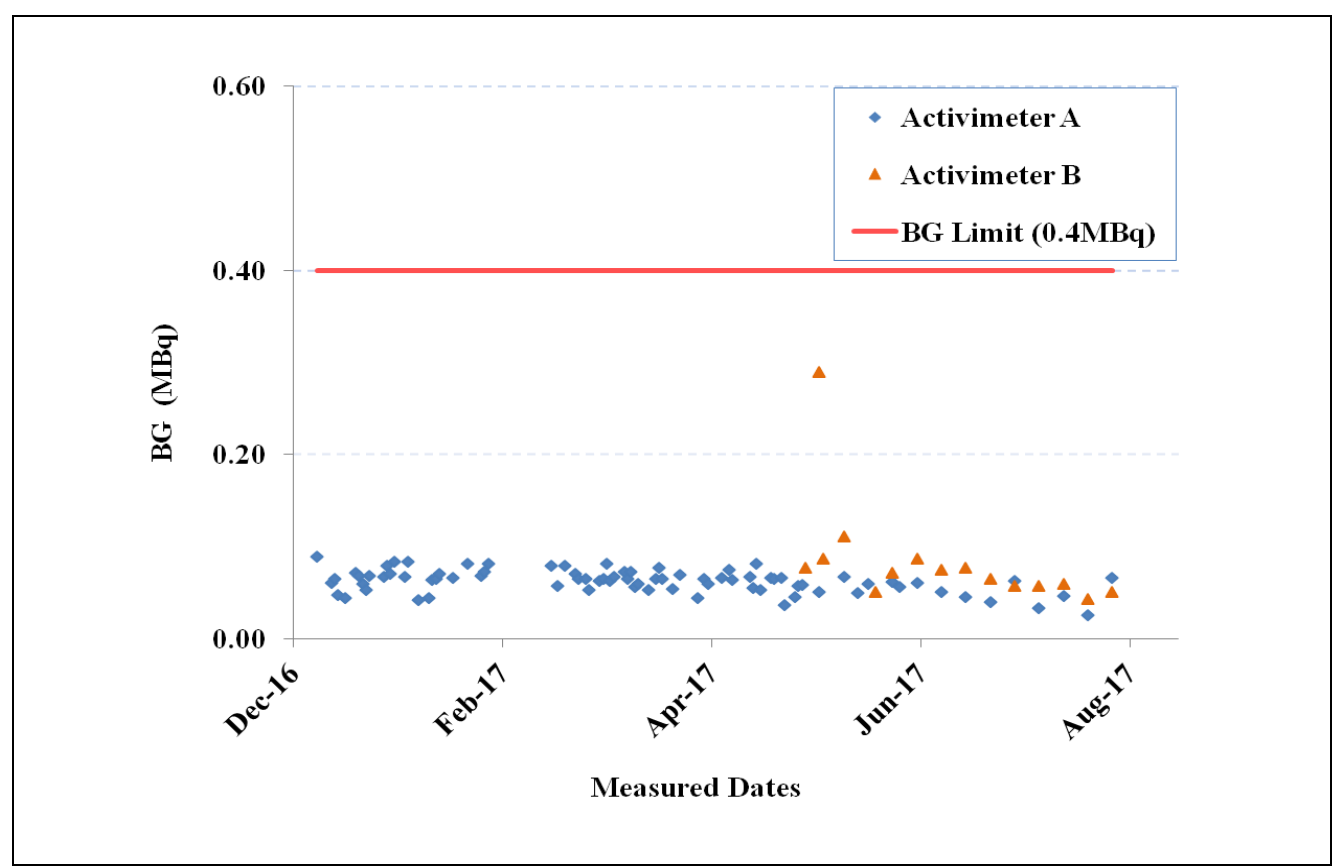


The only result above $0.20 \mathrm{MBq}$ was due to the presence of other radioactive sources when background test was performed.

Figure 5: Detector bias voltage check results for both activimeters.

(Upper and lower limits are established by manufacturer).

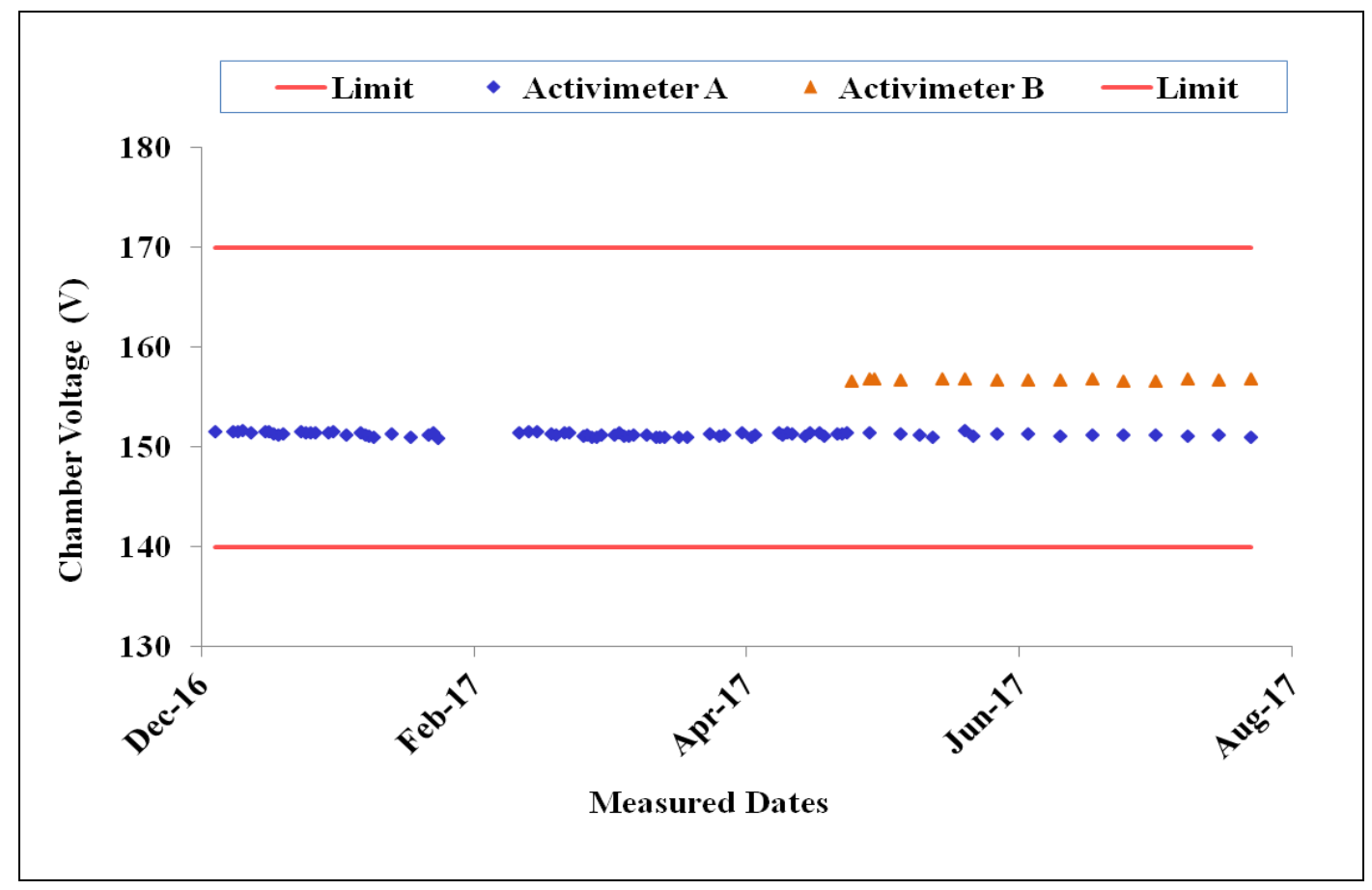

The equipments are located in different laboratories: one is in the radiopharmacy, activimeter A and the other is in the molecular imaging laboratory, activimeter B. However after the stabilization time of 30 minutes recommended by the manufacturer both activimeters had the performance results within the recommended limits.

\subsection{Repeatability Test}

Figures 6, 7 and 8 present the results for both activimeters based on known reference sources of ${ }^{57} \mathrm{Co},{ }^{133} \mathrm{Ba}$ and ${ }^{137} \mathrm{Cs}$, respectively. 
Figure 6: Results obtained for ${ }^{57}$ Co daily check in both activimeters.

The red line indicates the source activity calculated from the certified activity.

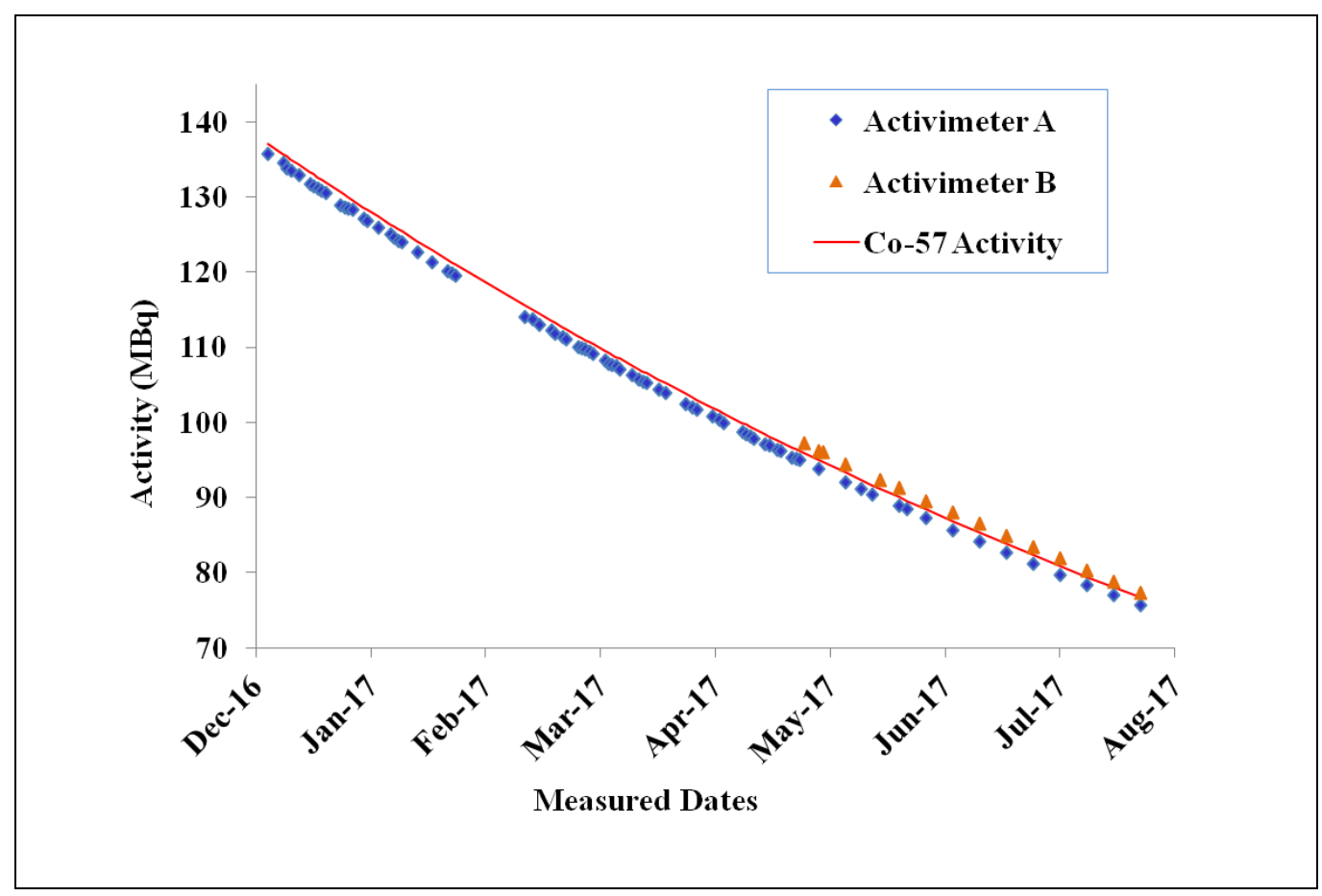

Figure 7: Results obtained for ${ }^{133}$ Ba daily check in both activimeters.

The red line indicates the source activity calculated from the certified activity.

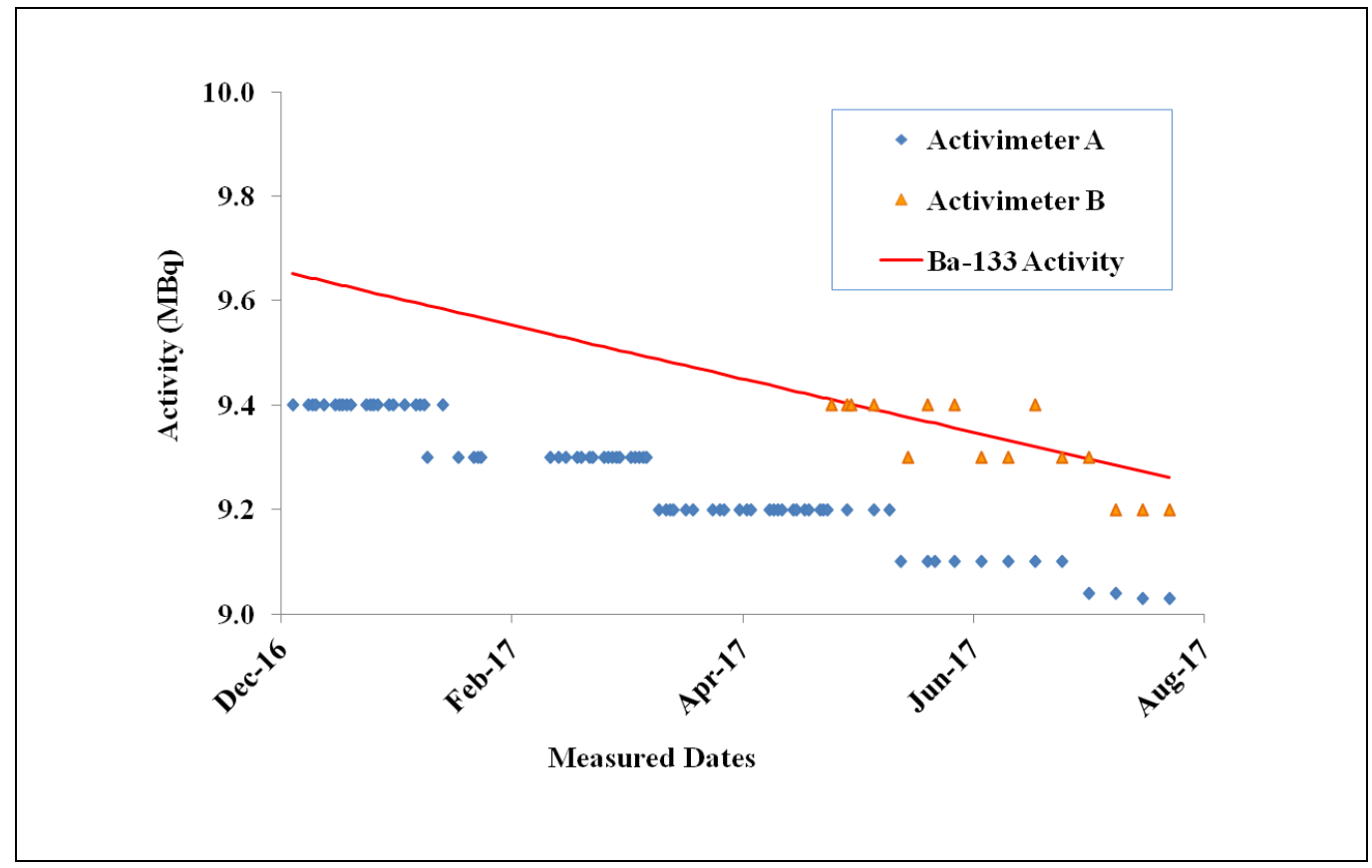


Figure 8: Results obtained for ${ }^{137}$ Cs daily check in both activimeters.

The red line indicates the source activity calculated from the certified activity.

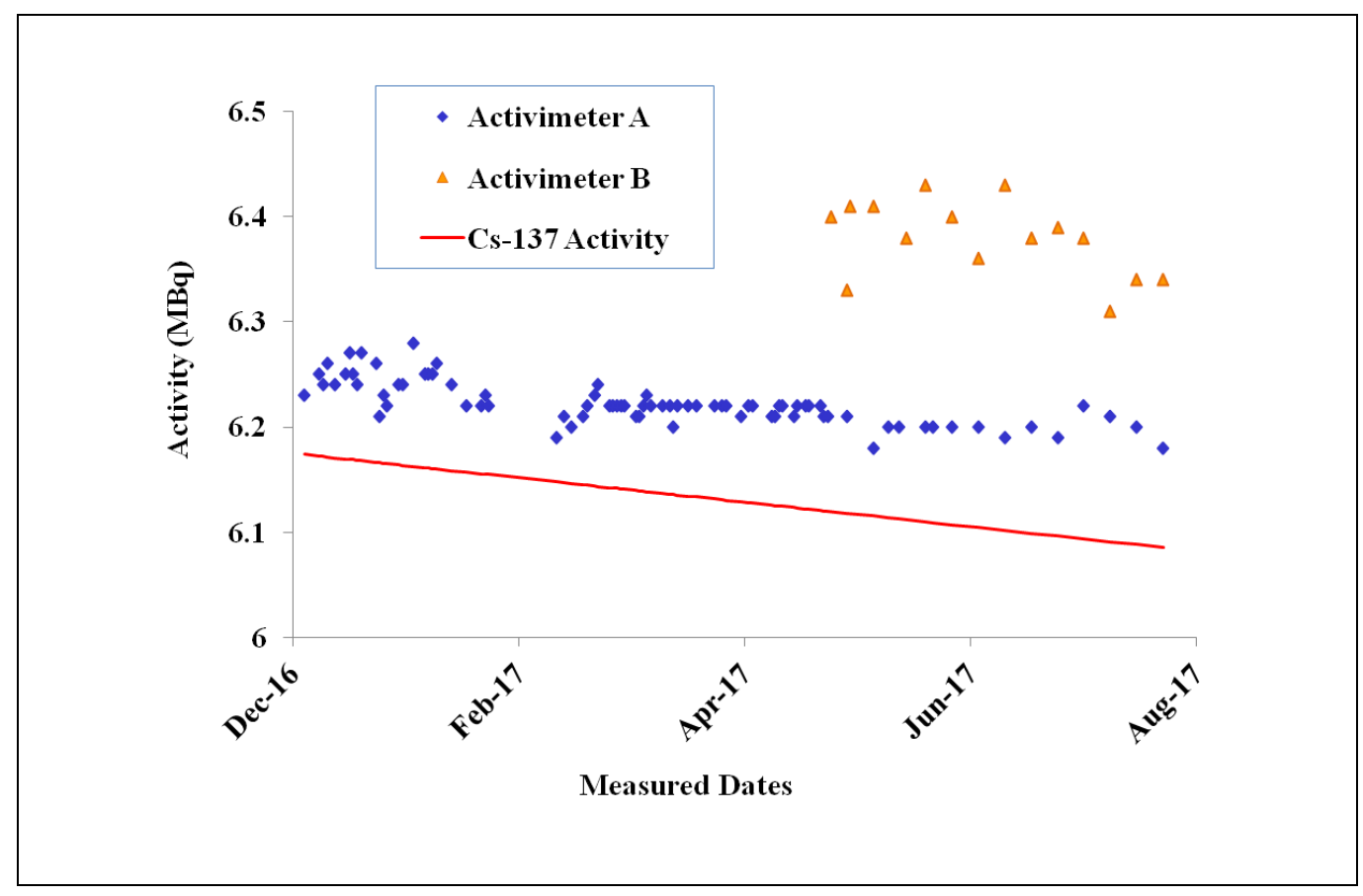

The purpose of the test is to check the operation constancy of a device over time, for different measurement conditions. Although the equipments show different results, all activity values from reference sources obtained in activimeters A and B were within the limits recommended by national and international standards.

\subsection{Accuracy and Precision Tests}

Table 4 shows results for accuracy and precision tests for both instruments. 
Table 4: Results obtained for the accuracy and precision tests in both activimeters.

\begin{tabular}{|c|c|c|c|c|}
\hline & \multicolumn{4}{|c|}{ Data measured for accuracy and precision } \\
\hline & \multicolumn{2}{|c|}{ First Semester } & \multicolumn{2}{|c|}{ Second Semester } \\
\hline & Activimeter A & Activimeter B & Activimeter A & Activimeter B \\
\hline & 6.24 & --- & 6.19 & 6.34 \\
\hline & 6.27 & --- & 6.16 & 6.32 \\
\hline & 6.26 & --- & 6.20 & 6.33 \\
\hline & 6.28 & --- & 6.19 & 6.35 \\
\hline & 6.25 & --- & 6.19 & 6.34 \\
\hline & 6.24 & --- & 6.18 & 6.35 \\
\hline & 6.27 & --- & 6.18 & 6.32 \\
\hline & 6.26 & --- & 6.20 & 6.33 \\
\hline & 6.26 & --- & 6.18 & 6.32 \\
\hline & 6.26 & --- & 6.17 & 6.33 \\
\hline Tests & \multicolumn{4}{|c|}{ Relative Standard Deviation of Activity (RSD) } \\
\hline Accuracy & -1.40 & --- & -1.41 & -3.94 \\
\hline Precision & 0.21 & --- & 0.20 & 0.18 \\
\hline
\end{tabular}

Results showed that the systems are accurate and precise in this period.

\subsection{Linearity test}

Figure 9 presents results of the linearity test for the activimeter A. 
Figure 9: Linearity for activimeter A.

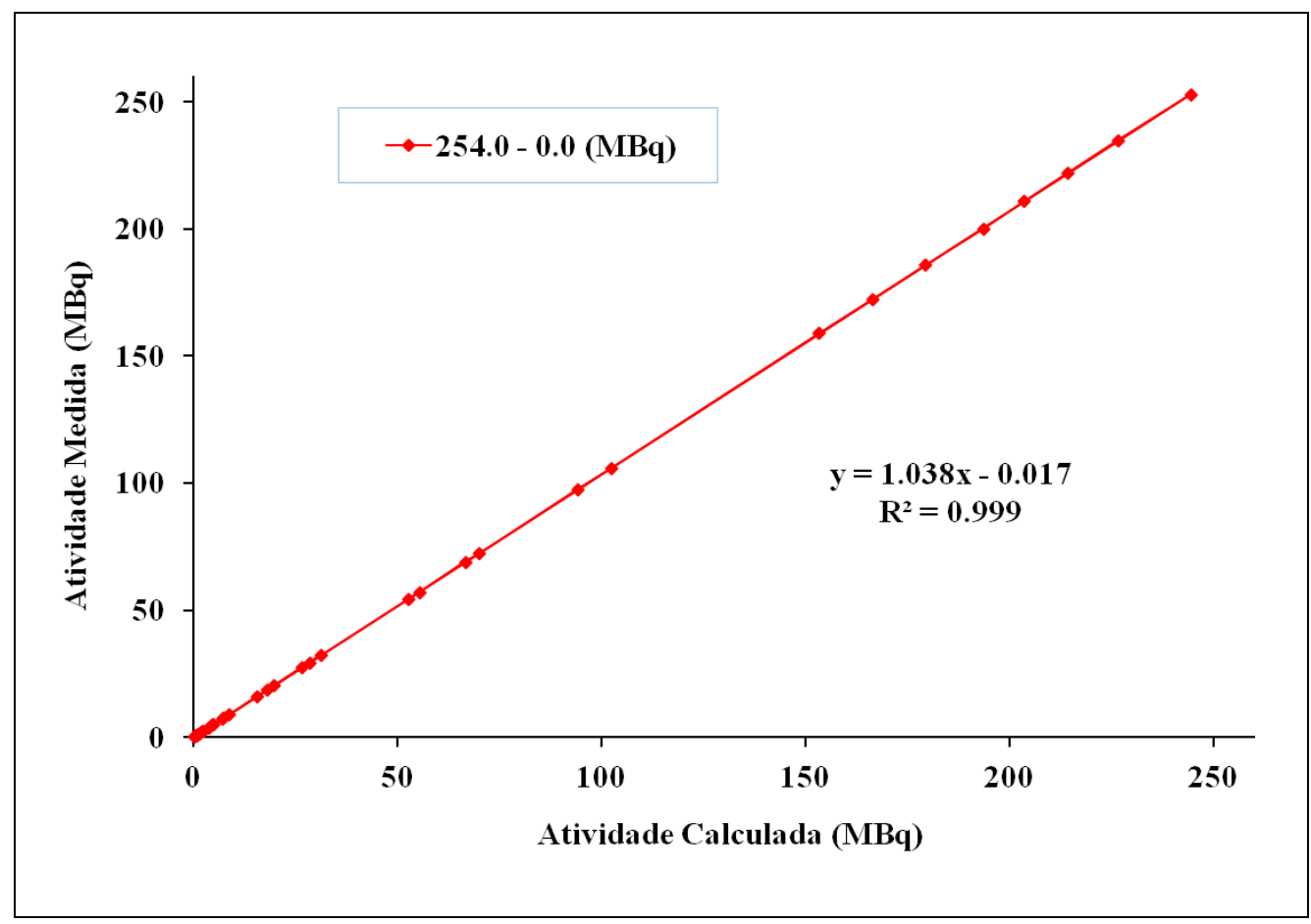

The results show a linear behavior in a large range of activity $(0.29$ to $250 \mathrm{MBq})$ for the tested activimeter. Linearity test of activimeter B will not be presented in this work.

\section{CONCLUSION}

The obtained results indicate that the UPPR's activimeters were stable over period evaluated. All values are within the limits presented by the manufacturer's manual and national standard for all tests done. This stability is of major importance for the reliability of all processes involved in molecular imaging.

In addition, a benchmark checklist was prepared to guide users and record the results of quality assurance testing to monitor the equipment performance. This task is part of the quality assurance program implemented at UPPR. 


\section{ACKNOWLEDGMENT}

The authors would like to thank the staff of the UPPR-CDTN/CNEN.

This work has supported and financed by FAPEMIG and CDTN/CNEN.

\section{REFERENCES}

[1] AAPM - American Association of Physicists in Medicine. The Selection, Use, Calibration, and Quality Assurance of Radionuclide calibrators used in Nuclear Medicine, Report of AAPM Task Group 181. June 2012.

[2] IAEA - International Atomic Energy Agency. Quality Assurance for Radioactivity Measurements in Nuclear Medicine. Technical Report Series No 454, Vienna, IAEA, 2007.

[3] IAEA - International Atomic Energy Agency. Quality Control of Nuclear Medicine Instruments. IAEA-TEC-DOC-602, Vienna, IAEA, 2007.

[4] CNEN - Comissão Nacional de Energia Nuclear. Requisitos de segurança e proteção radiológica para serviços de medicina nuclear, Norma CNEN NN 3.05. December, 2013.

[5] CAPINTEC, Inc. Owner’s Manual. Copyright 2006. Revision H, March 2015.

[6] IAEA - International Atomic Energy Agency. Live Chart of Nuclides. Available at: <https://www-nds.iaea.org>. Last accessed: 10 July 2017. 